\title{
كشافـ الناشرين
}

• د دار التقوى للطبع و النشر و التوزيع 199 rะт، ז

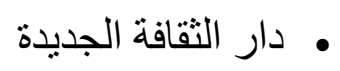
$\mid \mathrm{VI}, \mathrm{TV}$.

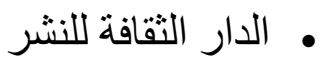

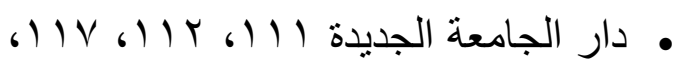
ITV 6ITE 6) T

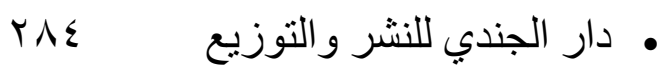

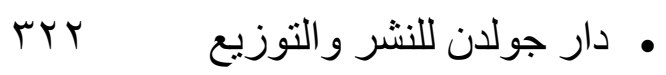

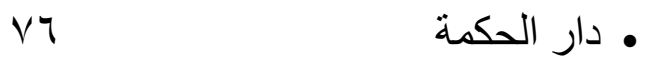
• دار الحكمة للطباعة والنشر و التوزيع $17 \leq 610461.4$

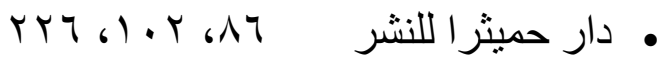

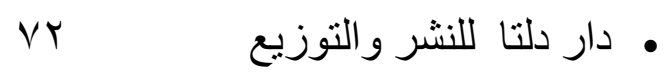
• دار الرسم بالكلمات للنشر والتوزيع $r \leqslant V$, $T \leqslant \varepsilon$

• دار رواف للنشر والتوزيع 107

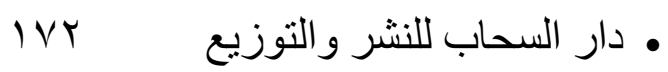

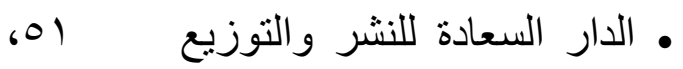
$\left.\leqslant T V_{6}\right) \vee \leqslant$ ،八 • دار السكرية للطباعة والنشر والتوزيع

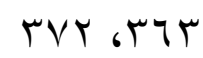

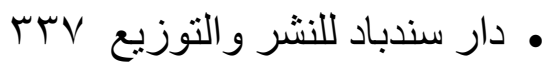

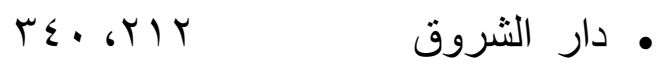

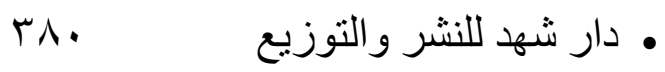

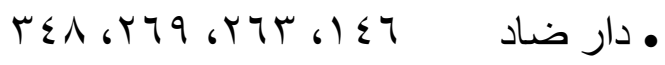

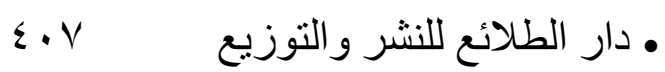

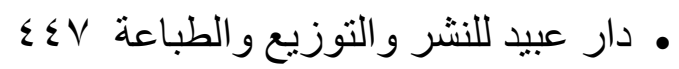

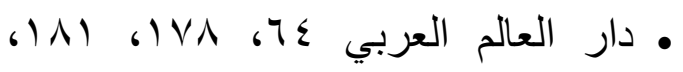

99 • إبداع للنشر والتوزيع

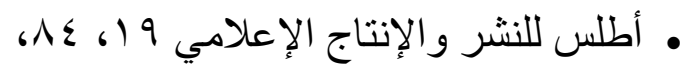

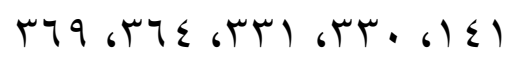

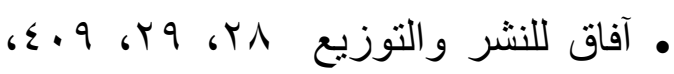
$\varepsilon r$. • الأكاديمية الحديثة للكتاب الجامعي 9V، $r \cdot 1$

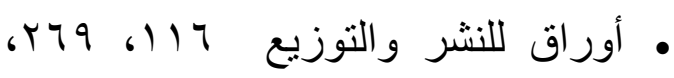
(T)

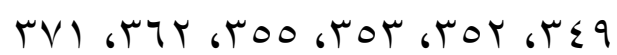
سمب

rol • تشرين للنشر و التوزيع

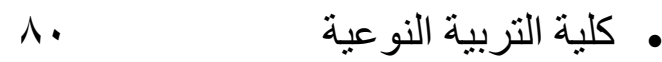
تنوير للنشر و الإعلام

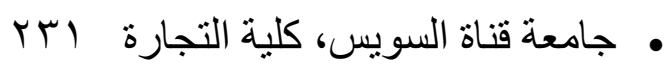

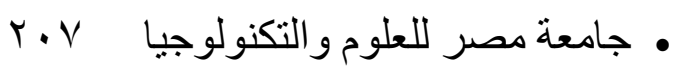

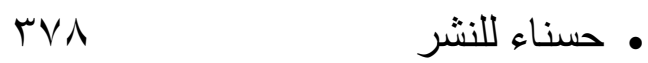

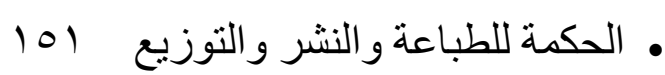

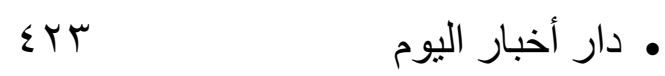

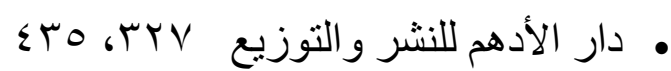

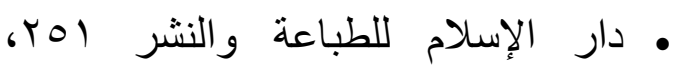

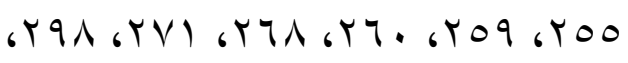
"

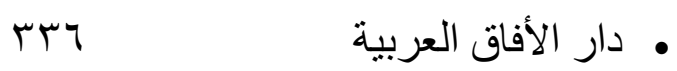

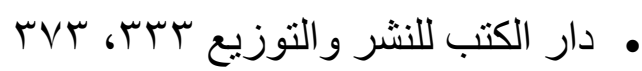

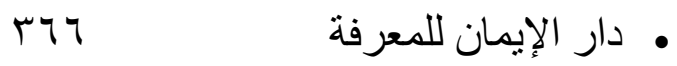

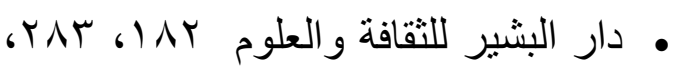

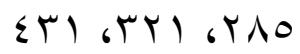


$\varepsilon r q$ ، $\varepsilon \cdot \Lambda$

• عالم لمار للنشر والتوزيع والترجمة

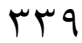

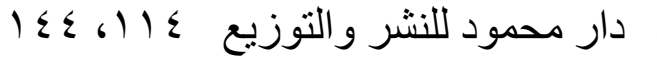

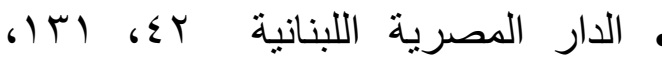
rNt r TVQ

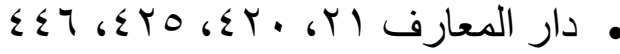

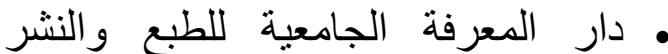
\&YV 6 21 , $T \leqslant$ و التوزيع • دار المؤسسة العربية للنشر والتوزيع lov

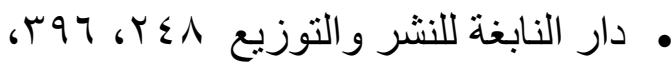
हा।

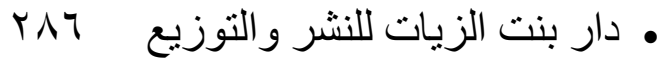
• دار النخبة للنشر والطباعة والتوزيع Yqะ 6 YVE 6 YTY

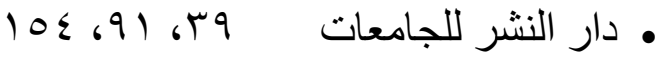

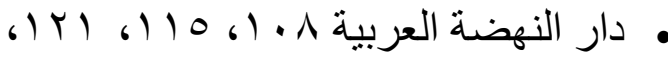

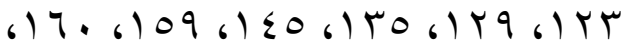

$$
19 \leq 619461716171
$$

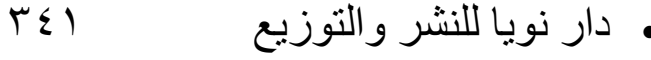

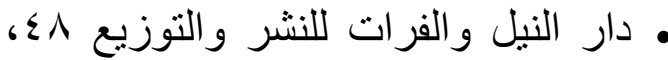
6 r. Y 6 Y T 6 YA9 6YVA 6YOT 6YO.

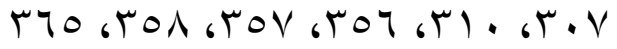

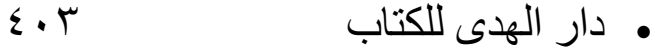

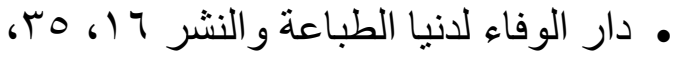

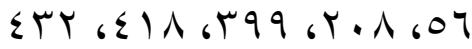

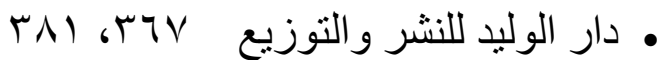

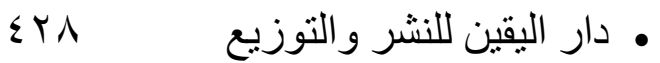

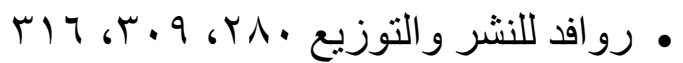

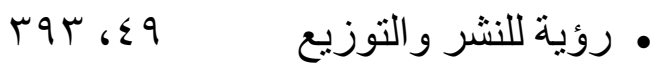

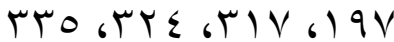

• دار عالم الثقافة للطباعة والنشر والتوزيع INT • الدار العالمية للنشر والتوزيع rr، rو، هوب،

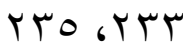

10 • دار العلم العربي

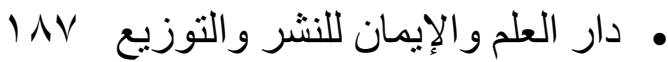

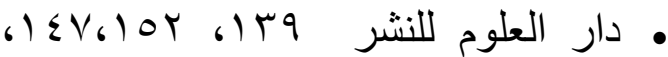
$r \leq 0$

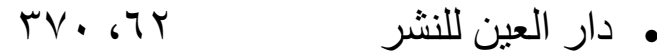

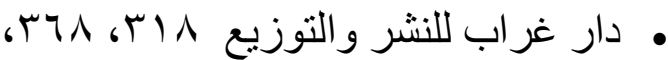
$\varepsilon \Sigma \cdot$ • เ $Y_{1}$

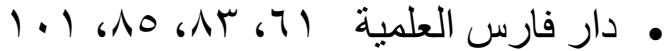
• دار الفتح للطباعة و النشر 119 • دار الفكر الجامعي 9 9

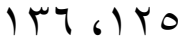

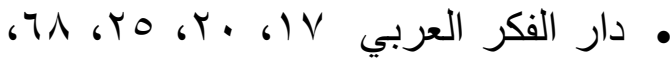
Y) 6)106 V. 69r

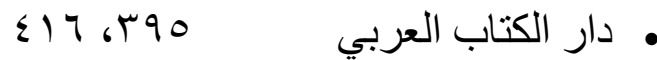

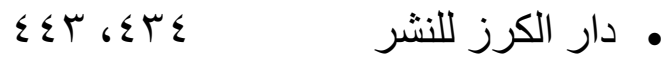

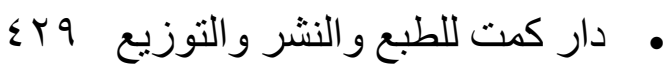

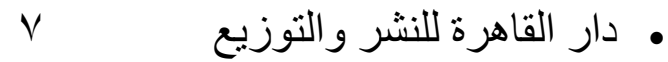

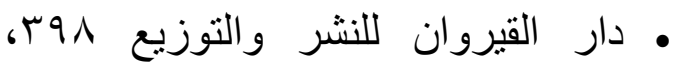
$\varepsilon$. 0 ، $\varepsilon$. $\varepsilon$

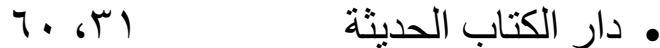

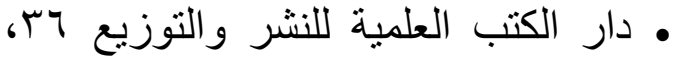

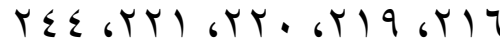

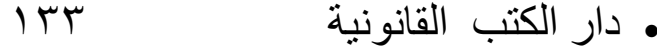

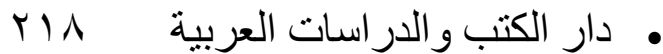

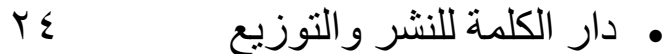

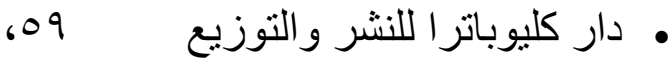




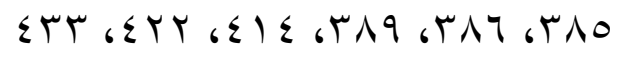

• مركز الكتاب الحديث

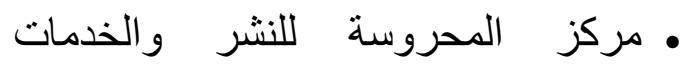

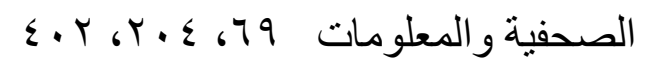

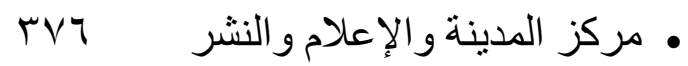

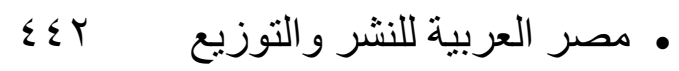
• مطابع الأهر ام التجارية

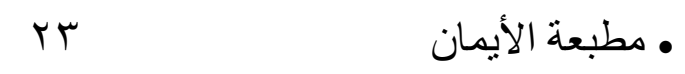

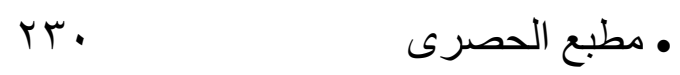

• معهد النيل العالي للهندسة و التكنولوجيا rIV

• المكتب العربي للمعارف المكين • المكتب المصري الحديث « 1

\section{• مكتبة ابن سينا

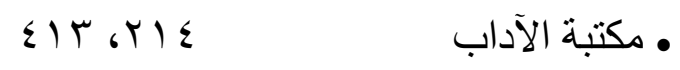 • مكتبة الانجلو المصرية البدابة}

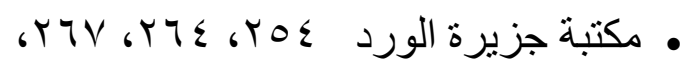

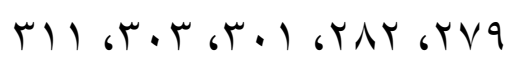

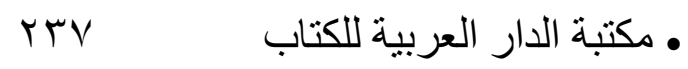

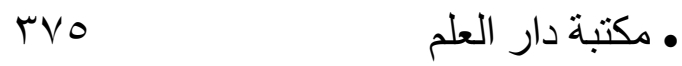
• مكتبة الثروق الدولية

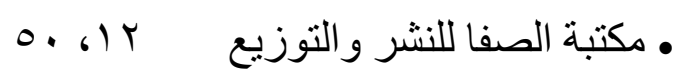
• مكتبة عبد الدايم

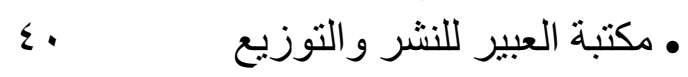

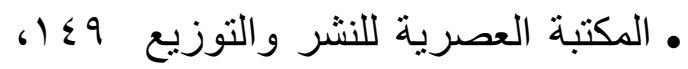
r

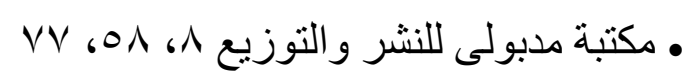

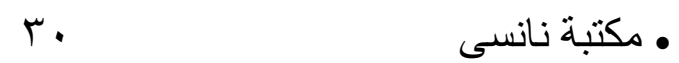

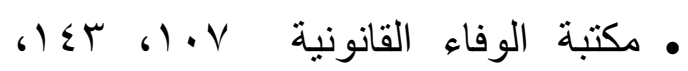
19161786100

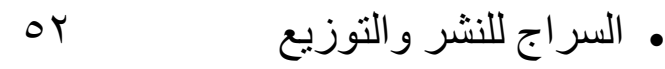

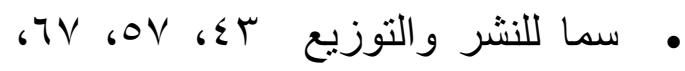
$\leq Y \leq 6 \varepsilon+1$

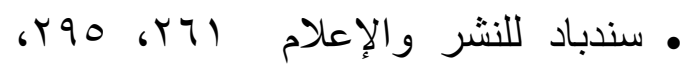

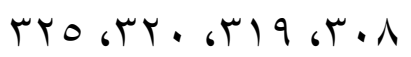

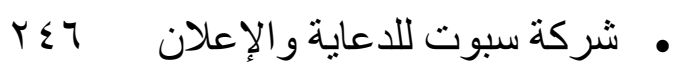

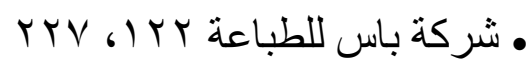

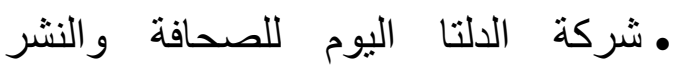
V. • الشركة العربية المتحدة للتسويق

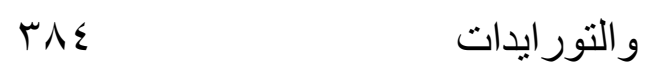
• شركة نو ابع الفكر

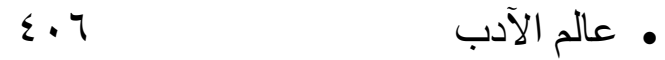

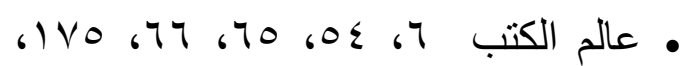
YYY 6 $9161 \wedge 161 \wedge T 6) V V$

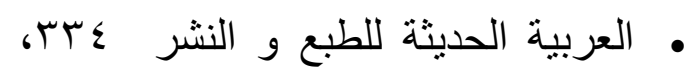

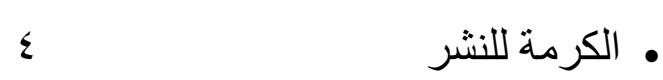

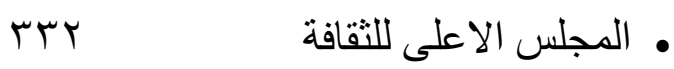

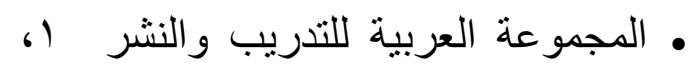

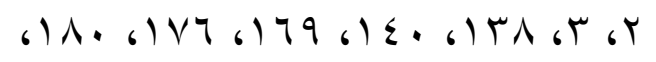

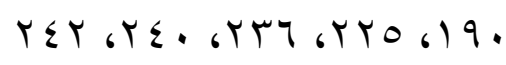

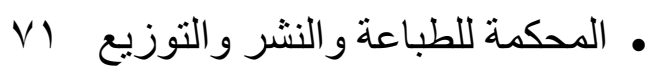

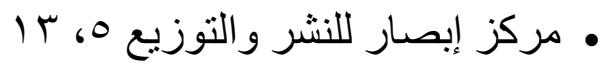

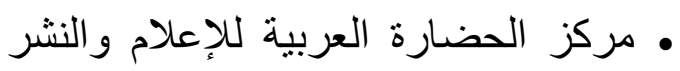
$1 \varepsilon$ و الدر اسات • مركز الدراسات العربية للنشر والتوزيع $\mid Y V$ (II (1).

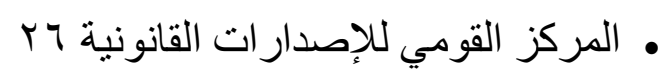

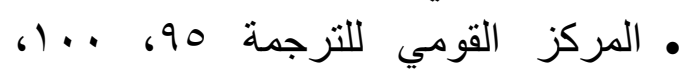

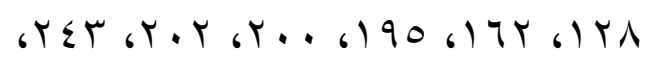




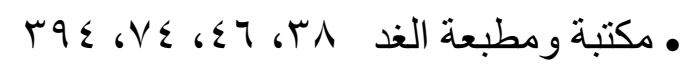
• منشأة المعارف • المركز الثقافي المصري للكتاب

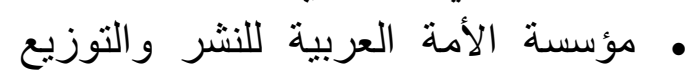
$r \leqslant Y$, TV • مؤسسة حورس الدولية

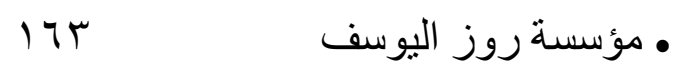

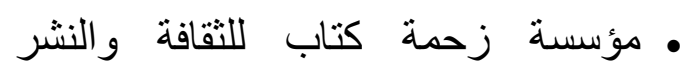
rET 6 TVT GYOV

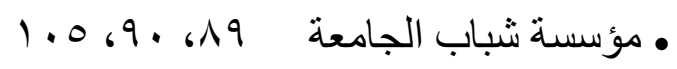

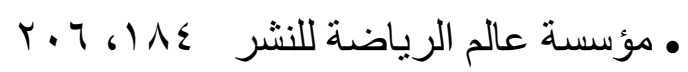

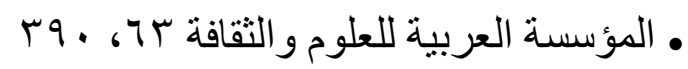

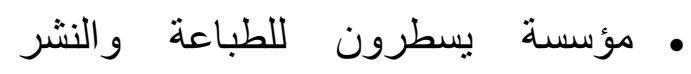

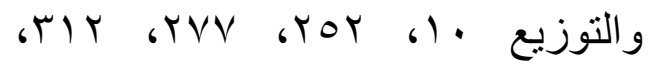

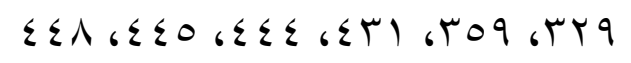

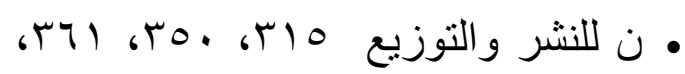
ש

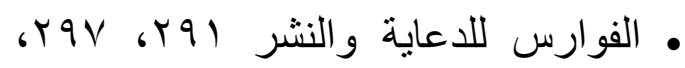
rit

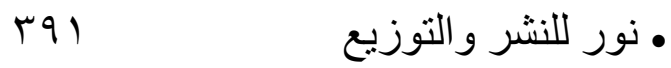

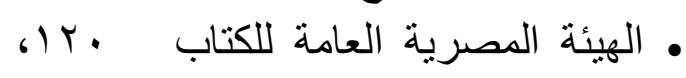

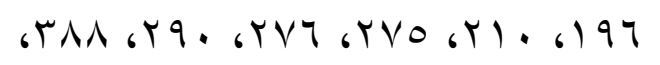
6ะYד $\varepsilon r \wedge$

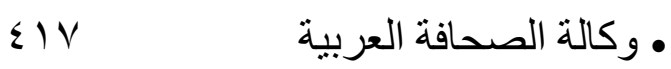

